\title{
The role of race and trust in tissue/blood donation for genetic research
}

\author{
Jada Bussey-Jones, $M D^{I}$, Joanne Garrett, $P h D^{2}$, Gail Henderson, PhD' ${ }^{2}$. Mairead Moloney, $M A^{2}$, \\ Connie Blumenthal, $\mathrm{MPH}^{2}$, and Giselle Corbie-Smith, $\mathrm{MD}^{2}$
}

\begin{abstract}
Background: Public willingness to donate tissue samples is critical to genetic research. Prior work has linked minority status and mistrust with less willingness to provide specimens. Some have suggested recruitment of prior research participants to address these barriers. We present data from a genetic epidemiology study with a request for blood and/or saliva specimens to (1) measure willingness to donate tissue/blood samples, (2) identify demographic, trust, and other factors associated with willingness to donate samples, and (3) measure willingness to participate in future genetic research. Methods: We surveyed participants in the North Carolina Colorectal Cancer Study, which included biologic sample collection from consenting participants. Participants were later asked about sample provision; trust in researchers, and future research participation. Results: African Americans were less likely to give a blood sample, when compared with whites $(21 \%$ vs. $13 \%, P<$ $0.05)$. After controlling for "trust," this difference was no longer statistically significant $(17 \%$ vs. $13 \%, P=0.27)$. Those who had given samples were more likely to express willingness to participate in future research. Conclusion: Despite prior participation in a genetic epidemiology study, factors associated with provision of tissue samples reflected many previously identified demographic factors (race and trust). Interventions to improve and demonstrate the trustworthiness of the research team and recruitment of subjects with a record of sample donation might enhance future study participation. Genet Med 2010: 12(2):116-121.
\end{abstract}

Key Words: trust, research participation, biologic samples, genetics

$\mathrm{P}$ ublic approval of and willingness to participate in studies that collect and store biological specimens are crucial for the viability of genetic research. Prior work demonstrates a general support for and favorable views of genetic research. ${ }^{1-4}$ However, although general support seems high, less than half of individuals are willing to donate when a specific request for blood donation and storage is made. ${ }^{5}$ Furthermore, a number of studies have demonstrated that minority status and mistrust regarding potential outcomes of genetic research, among other factors, have been linked to lower rates of participation in genetic research and less willingness to provide specimens. ${ }^{1,6-9}$

General endorsement of, participation in, and donation of biological specimens for genetic research likely represent a continuum of views that may overlap or diverge even in the same individual. Some have suggested a strategy of recruiting

From the ${ }^{1}$ School of Medicine, Emory University, Atlanta, Georgia; and ${ }^{2}$ University of North Carolina, Chapel Hill, North Carolina.

Jada Bussey-Jones, MD, Emory University School of Medicine, 49 Jessie Hill Jr. Drive, Atlanta, GA 30331. E-mail: jcbusse@emory.edu.

Disclosure: The authors declare no conflict of interest.

Submitted for publication July 15, 2009.

Accepted for publication December 1, 2009.

Published online ahead of print January 21, 2010.

DOI: 10.1097/GIM.0b013e3181cd6689 prior research subjects to increase the likelihood of research participation and minimize the impact of the aforementioned barriers. Those with a history of participation in research studies may be more positive about requests for biological specimens and more willing participants in future genetic studies than the general population. ${ }^{10-13}$ However, even among participants in research that requests biological specimens, the response may be variable, and this variability may impact future recruitment. Few studies have examined the extent of that variation and the factors that may underlie different choices made by participants. Some explored only theoretical consent to donation and use of biological specimens. ${ }^{4,5}$ Others examined actual tissue donation but did not explore factors associated with consent ${ }^{14}$ or focused only on conventional demographic factors. ${ }^{1}$

We report herein on interviews that explore this issue for participants in a genetic epidemiology study, which included an actual request for blood and/or saliva specimens. We evaluate their responses to this request and explore demographic variables, trust, and other factors associated with willingness to donate samples and how likely they would be to participate in a genetic research study in the future. Finally, we use responses to open-ended questions to contextualize our quantitative findings. We focused primarily on the characteristics and reservations of those unwilling to donate to facilitate discussions about future interventions designed to overcome reluctance to donate and participate.

\section{METHODS}

\section{Learning about research in North Carolina and North Carolina colorectal cancer study sample}

Learning About Research in North Carolina (LeARN) is a cross-sectional study of African American and white participants who had recently participated in a case-control genetic epidemiology study of colon cancer risk factors, the North Carolina Colorectal Cancer Study (NCCCS). The methods are fully described elsewhere. ${ }^{15}$ In brief, in the NCCCS study, cases had an initial diagnosis of invasive rectosigmoid cancer. Age, race, and sex-matched controls were selected from two sources: Division of Motor Vehicles records for those younger than 65 years and Center for Medicare and Medicaid Services tapes for those aged 65 years and older. Race/ethnicity was initially obtained from cancer registry records and Division of Motor Vehicles or Center for Medicare and Medicaid Services files and further confirmed by self-identification during the interview. In the case of conflicting data, the participants' selfidentified race was used. The NCCCS participants completed a 2-hour in-person interview that collected data on demographics, dietary, lifestyle and environmental exposure, and health care access and utilization. Blood and/or a mouthwash sample were obtained from consenting participants at the conclusion of the interview. DNA and serum were stored for future analyses.

Participants for the LeARN telephone interviews were identified through the NCCCS database of participants interested in hearing 
about other studies. They were eligible if they met the following criteria: (1) self-reported race of African American or non-Latino white, (2) completed the entire interview required of the NCCCS, (3) agreed to be contacted about future studies, (4) lived in the state of North Carolina at the time of the LeARN study, and (5) had sufficient cognitive functioning, as assessed by the interviewer, to allow successful completion of the telephone interview.

Potential participants were mailed a letter by the NCCCS investigators that introduced the LeARN study, described the telephone interview, and alerted them to expect a follow-up telephone call. Participants were given a toll-free number to call the NCCCS offices and invited to call with questions or if they did not wish to be contacted. Potential participants were contacted on average 4 months after completing the NCCCS interview. During the initial phone call, the nature and purpose of the LeARN study were explained, and verbal consent was sought. Each participant was offered an incentive of $\$ 25$, which was mailed after completion of the interview. We contracted with a professional survey group, FGI, Inc., to conduct the telephone surveys, using Computer-Assisted Telephone Interviewing methods. The surveys consisted of both closed- and open-ended questions. For those who refused, interviewers made at least 10 attempts to contact each person and performed one refusal conversion attempt per refusal. All interviews were audio taped and transcribed for content analysis of the open-ended questions. All procedures were approved by the University of North Carolina Institutional Review Board.

\section{Measures}

In the LeARN survey questions on whether a participant had given a blood and/or mouthwash sample for NCCCS were included. For those who had not given a sample, we asked openended questions to determine why they had not. In addition, we asked several questions on attitudes about trust of research and researchers and perceptions of potential discrimination that could occur by participating in a genetic research study. We also asked participants "If you were asked to take part in a genetic research study, the kind that looks at whether genes that are passed down through families put people at risk for diseases or illnesses, how likely would you be to take part in such a study in the future?"

\section{Analysis}

We used frequencies to describe demographic information (e.g., race, gender, and education) and other characteristics, such as case/control status and perceived health status. We then used Pearson's $\chi^{2}$ tests to assess associations between each of the participant characteristics and the responses to whether they had contributed a blood and/or a mouthwash sample for NCCCS. In addition, to explore whether trust was a factor in participants' decision to provide a sample, we used Pearson's $\chi^{2}$ tests to compare each of nine questions about lack of trust of medical research and researchers to whether or not a participant donated a sample. Each question was coded as 1 for "agree" with a statement about lack of trust and 0 for "disagree" or "don't know." We also examined the association of each of the trust questions to race. Given that our hypothesis was that African Americans would be less likely than whites to donate samples and that they would also be likely to have less trust in research and researchers, we used a logistic regression model with donating a blood sample as the outcome (yes/no) and race as the main study factor, controlling for the questions on trust. Our goal was to see whether any observed association between race and sample donation was confounded by lack of trust. We were also interested in seeing whether participants who had contributed a sample were more likely to express willingness to participate in future genetic research studies. Because a large majority of participants said they were at least somewhat likely to participate in future studies $(89 \%)$, we dichotomized this response into "very likely" versus all other responses. We used Pearson's $\chi^{2}$ tests to compare sample donation to percent likely to participate in future studies, first overall, and then stratified by race. Finally, we examined the open-ended questions to further explore respondents' reasons for not giving a blood or mouthwash sample.

\section{Qualitative analysis}

Qualitative analysis was performed to more fully understand the views and responses of the 112 participants who refused to provide at least one type of biological sample. We qualitatively analyzed responses to the open-ended question "What were your reasons for not giving blood?" Codes were initially developed a priori by the team of LeARN investigators, applied, and validated through an iterative process. Seven coders applied the codes to all responses to openended questions; periodic checks were undertaken to assure uniformity of application and accuracy of coding by the LeARN investigators. Additionally, there was a final review of each of the transcripts by race to determine whether African Americans and whites and to determine whether there were different patterns of responses.

\section{RESULTS}

The overall response rate in the LeARN study was $73 \%$. The final sample of 801 had a mean age of 64 years. Respondents included 19\% African Americans and 81\% whites; 57\% were men (Table 1). The majority had at least a high school education, and $28 \%$ had a college degree. About half the sample had an annual income of less than $\$ 40,000$. Most were "very" (53\%) or "somewhat" $(42 \%)$ religious.

\section{NCCCS blood or mouthwash samples}

Overall, $15 \%$ of the participants did not give a blood sample, $8 \%$ did not give a mouthwash sample, and only $3.5 \%$ did not give either. African Americans were less likely to give a blood sample, when compared with whites $(21 \%$ vs. $13 \%, P<0.05)$ (Table 1). Other than this observed racial difference, there were no significant differences in blood or mouthwash donation by any of the other demographic characteristics.

However, we did observe several associations when we compared responses with LeARN survey questions on trust in medical research to providing blood and/or a mouthwash sample during NCCCS. Those who felt less trust for research and researchers were less likely to have given a sample (Table 2). For example, when asked whether they agreed with the statement, "The government cannot be trusted to regulate the use of genetic information," $18 \%$ who agreed had not given a blood sample versus $12 \%$ of those who did not agree. There were pronounced differences between African Americans and whites in their responses to the trust questions, with African Americans consistently showing less trust (Table 3 ).

We used a logistic regression model to examine the relationship between race and blood donation adjusted for the trust variables and found the estimated differences between African Americans and whites was smaller, when compared with the unadjusted estimates. This adjusted difference (17\% no blood sample in African Americans vs. 13\% no blood sample in whites) was no longer statistically significant $(P=0.27)$. None of the other participant characteristics, including case status, confounded the original racial differences. Although African 
Table 1 Participant demographic characteristics and their associations with no blood and/or mouthwash samples given during NCCCS

\begin{tabular}{lcccc}
\hline $\begin{array}{l}\text { Participant } \\
\text { characteristics }\end{array}$ & $n(\%)$ & $\begin{array}{c}\% \text { No } \\
\text { blood } \\
\text { sample }\end{array}$ & $\begin{array}{c}\% \text { No } \\
\text { mouthwash } \\
\text { sample }\end{array}$ & $\begin{array}{c}\% \text { No } \\
\text { blood or } \\
\text { mouthwash }\end{array}$ \\
\hline Race & $153(19)$ & $21^{a}$ & 9 & 6 \\
$\quad \begin{array}{l}\text { African American } \\
\text { White }\end{array}$ & $648(81)$ & 13 & 8 & 3
\end{tabular}

Case status

$\begin{array}{lllll}\text { Case } & 363(55) & 15 & 9 & 3 \\ \text { Control } & 438(45) & 14 & 7 & 4\end{array}$

Race and case

$\begin{array}{lcccc}\text { Black cases } & 84(10) & 18 & 11 & 5 \\ \text { Black controls } & 69(9) & 24 & 7 & 6 \\ \text { White cases } & 279(35) & 14 & 8 & 3 \\ \text { White controls } & 369(46) & 12 & 7 & 3\end{array}$

Gender

$\begin{array}{lllll}\text { Male } & 457(57) & 14 & 8 & 3 \\ \text { Female } & 344(43) & 15 & 7 & 4\end{array}$

Education

$\begin{array}{lllll}\text { Less than high school } & 118(15) & 15 & 11 & 8 \\ \text { High school grad } & 197(25) & 13 & 10 & 3 \\ \text { More than high school } & 258(32) & 16 & 7 & 4 \\ \text { College and higher } & 228(28) & 13 & 6 & 2\end{array}$

Household income

$\begin{array}{lllll}<\$ 20,000 & 147(21) & 16 & 8 & 3 \\ \$ 20,000-\$ 40,000 & 183(27) & 16 & 9 & 4 \\ >\$ 40,000 & 361(52) & 14 & 7 & 3\end{array}$

Current health status

$\begin{array}{lcccc}\text { Excellent } & 105(13) & 15 & 7 & 4 \\ \text { Very good } & 294(37) & 15 & 5 & 4 \\ \text { Good } & 235(30) & 14 & 10 & 5 \\ \text { Fair } & 113(14) & 16 & 11 & 2 \\ \text { Poor } & 45(6) & 14 & 9 & 0\end{array}$

How religious

\begin{tabular}{lcccc} 
Not religious & $40(5)$ & 19 & 8 & 8 \\
Somewhat religious & $326(42)$ & 17 & 9 & 4 \\
Very religious & $413(53)$ & 12 & 7 & 3 \\
\hline${ }^{{ }^{P}<<0.05 .}$ & &
\end{tabular}

Americans were still somewhat less willing than whites to donate blood after controlling for the trust variables, much of the unadjusted discrepancy might be explained by less trust in research and researchers.
Table 2 Associations between no blood and/or mouthwash samples given during NCCCS and participant responses to questions on trust and discrimination

\begin{tabular}{lll}
\hline $\begin{array}{l}\text { General questions on } \\
\text { trust/discrimination }\end{array}$ & $n \begin{array}{l}\% \text { No } \% \text { No } \\
\text { blood mouthwash \% Neither }\end{array}$ \\
\hline
\end{tabular}

Lose insurance coverage by taking part in study

$\begin{array}{lrrrr}\text { Agree } & 153 & 17 & 10 & 5 \\ \text { Do Not Agree/Don't Know } & 608 & 14 & 7 & 3\end{array}$

Lose privacy when giving a sample for research

$\begin{array}{lrrrr}\text { Agree } & 179 & 18 & 12^{a} & 8^{b} \\ \text { Do Not Agree/Don't Know } & 585 & 13 & 7 & 2\end{array}$

Shouldn't do research until we know how info used

Do Not Agree/Don't Know

$\begin{array}{llll}368 & 18^{b} & 9 & 4 \\ 391 & 11 & 7 & 3\end{array}$

Government can't be trusted to regulate use of genetic info

$\begin{array}{lllll}\text { Agree } & 287 & 18^{a} & 8 & 5 \\ \text { Do Not Agree/Don’t Know } & 468 & 12 & 8 & 3\end{array}$

Trust medical researchers

$\begin{array}{lrrrr} & 707 & 14 & 7^{b} & 3^{b} \\ \text { Do Not Agree/Don't Know } & 56 & 18 & 17 & 11\end{array}$

Research participants may be deceived by researchers

Agree

$\begin{array}{llll}226 & 19^{a} & 8 & 5\end{array}$

$\begin{array}{llll}533 & 13 & 7 & 3\end{array}$

Researchers want to know more than they need to know

$\begin{array}{lrrrr}\text { Agree } & 145 & 21^{b} & 11 & 8^{b} \\ \text { Do Not Agree/Don't Know } & 619 & 13 & 7 & 2\end{array}$

Researchers do harmful experiments w/o patient's knowledge

$\begin{array}{lllll}\text { Agree } & 194 & 16 & 7 & 5 \\ \text { Do Not Agree/Don't Know } & 569 & 14 & 8 & 3\end{array}$

Medical researchers use minorities as guinea pigs

\begin{tabular}{lrrrr} 
Agree & 77 & $23^{a}$ & 10 & $11^{b}$ \\
Do Not Agree/Don't Know & 684 & 13 & 8 & 3 \\
\hline${ }^{a} P<0.05$. \\
${ }^{b} P<0.01$.
\end{tabular}

\section{Willingness to participate in future genetic studies}

When we asked participants about how likely they would be to take part in future genetic research studies, those who had given samples in NCCCS were more likely to express willing- 
Table 3 Associations between race and participant responses to questions on trust and discrimination

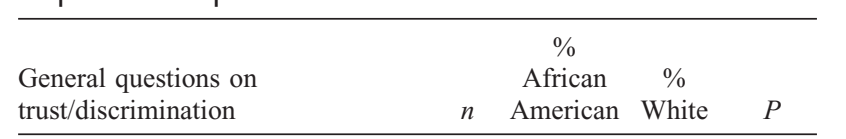

Lose insurance coverage by taking part in study

$\begin{array}{lllll}\text { Agree } & 153 & 28 & 19 & 0.014 \\ \text { Do Not Agree/Don't Know } & 608 & 72 & 81 & \end{array}$

Lose privacy when giving a sample for research

$\begin{array}{lllll}\text { Agree } & 179 & 29 & 22 & 0.067 \\ \text { Do Not Agree/Don't Know } & 585 & 71 & 18 & \end{array}$

Shouldn't do research until we know how info used

$\begin{array}{lllll}\text { Agree } & 368 & 67 & 44 & <0.001 \\ \text { Do Not Agree/Don't Know } & 391 & 33 & 56 & \end{array}$

Government can't be trusted to regulate use of genetic info

$\begin{array}{lllll}\text { Agree } & 287 & 49 & 35 & <0.001 \\ \text { Do Not Agree/Don't Know } & 468 & 51 & 65 & \end{array}$

Trust medical researchers

$\begin{array}{lrrrr}\text { Agree } & 707 & 87 & 94 & 0.007 \\ \text { Do Not Agree/Don’t Know } & 56 & 13 & 6 & \end{array}$

Research participants may be deceived by researchers

$\begin{array}{lllll}\text { Agree } & 226 & 44 & 27 & <0.001 \\ \text { Do Not Agree/Don't Know } & 533 & 56 & 73 & \end{array}$

Researchers want to know more than they need to know

Agree

$\begin{array}{llll}145 & 36 & 15 & <0.001 \\ 619 & 64 & 18 & \end{array}$

Do Not Agree/Don't Know

Researchers do harmful experiments w/o patient's knowledge

\begin{tabular}{lrrrr} 
Agree & 194 & 40 & 22 & $<0.001$ \\
$\begin{array}{l}\text { Do Not Agree/Don't Know } \\
\text { Medical researchers use minorities }\end{array}$ & 569 & 60 & 78 & \\
$\quad$ as guinea pigs & & & & \\
Agree & 77 & 27 & 6 & $<0.001$ \\
Do Not Agree/Don't Know & 684 & 73 & 94 & \\
\hline
\end{tabular}

ness to participate. These differences were particularly evident among the African American participants (Table 4). Controlling for participant characteristics and the trust variables in a logistic regression model did not change any of these results.

\section{Qualitative responses}

There were 112 participants who refused to provide at least one type of biological sample (32 provided a blood sample but no mouthwash and 80 provided mouthwash but no blood). Additionally, 26 participants provided neither. Of the 80 participants who did not give a blood sample but did give a mouthwash sample, 36 responded to the open-ended question: "What were your reasons for not giving blood?" Responses to the open ended question were brief with the average response of 3.6 sentences. There were several common themes. More than one third reported offering to have blood drawn, but there was a problem finding a vein. Others, primarily cancer cases or those with debilitating medical conditions, said that they did not feel well enough to have another blood draw. Several admitted to not liking needles. Some were vague and said that they "just didn't want to do it" or planned to do it another time. A few expressed concerns about "privacy" by responding with answers such as "Because they couldn't tell me when and how they were going to use it" and "I just didn't want to give, I didn't want anybody I didn't know sticking me."

Fourteen of the 26 participants who did not give either a blood or mouthwash sample answered the open-ended questions. Some respondents ( 5 of 14) said that they did not recall a request for samples ("I wasn't asked to give any"). However, the majority (9 of 14) gave responses that suggest concerns, from general unease to unambiguous suspicion. Sample responses include, "I'm very careful though [about] who puts anything in my mouth, you know? I don't know you people ..." Another respondent stated "I don't donate blood. It's my opinion. What I want for my body or what I want for me is entirely up to me. ... I'm very skeptical because doctors make so many mistakes." When examining the responses by race, we were unable to identify a clear pattern of responses.

\section{DISCUSSION}

In this study, we were able to explore factors associated with refusals to provide blood and/or mouthwash samples among genetic research study participants and its relationship to future research participation. We found that respondents who were unwilling to provide biological specimens were more likely to be African American and less trusting of medical researchers and were also less likely to be willing to participate in future genetic research. Furthermore, the discrepancy between African Americans and whites for blood sample donations was explained in part by less trust in medical research and researchers. Thus, despite prior participation in a genetic epidemiology study (NCCCS), factors associated with willingness to provide tissue samples reflected many demographic factors previously identified in research on public attitudes toward genetic research. This study enhances this prior work by adding trust to an examination of traditional demographic variables and adding open-ended questions that provide more detailed explanation of participant refusals. In these open-ended queries, we found generic concerns about needle sticks and inconvenience, as well as themes of discomfort and mistrust.

Prior research on public attitudes toward requests for biological specimens for research and long-term storage has examined how responses might vary based on the request and the respondent. African American race, female gender, older age, lower income, less education, higher occupation category, and worse health status have been associated with less willingness to consent to donate and store specimens. ${ }^{1,16}$ Researchers have documented public belief in the potential of genetic research to contribute to improved health ${ }^{6,7,10}$ but consistently lower acceptance among minority groups. ${ }^{1,5,6,16,17}$ One study analyzed consent forms and found that, although $87 \%$ of 1670 subjects authorized future use for any medical condition, fewer African 
Table 4 Association between blood and/or mouthwash samples given and being very likely to participate in future genetic research studies

\begin{tabular}{|c|c|c|c|c|c|c|c|c|c|}
\hline \multirow[b]{2}{*}{ Type of sample } & \multicolumn{3}{|c|}{ Overall } & \multicolumn{3}{|c|}{ African American } & \multicolumn{3}{|c|}{ White } \\
\hline & $n$ & \% Very likely & $P$ & $n$ & \% Very likely & $P$ & $n$ & $\%$ Very likely & $P$ \\
\hline \multicolumn{10}{|l|}{ Blood } \\
\hline Yes & 628 & 51 & 0.019 & 113 & 47 & 0.042 & 515 & 52 & 0.170 \\
\hline No & 106 & 39 & & 30 & 27 & & 76 & 43 & \\
\hline \multicolumn{10}{|l|}{ Mouthwash } \\
\hline Yes & 679 & 50 & 0.010 & 127 & 48 & 0.011 & 552 & 51 & 0.118 \\
\hline No & 56 & 32 & & 14 & 14 & & 42 & 38 & \\
\hline \multicolumn{10}{|c|}{ Blood and mouthwash } \\
\hline Yes & 687 & 50 & 0.008 & 130 & 45 & 0.051 & 557 & 51 & 0.062 \\
\hline No & 23 & 22 & & 8 & 13 & & 15 & 27 & \\
\hline
\end{tabular}

Americans $(75 \%)$ did so. ${ }^{18}$ Our study mirrors these racial differences; however, further exploration of trust seems to be important in explaining these differences. Furthermore, our study explicitly examines the role of race and trust among a population of prior research participants, presumed to be more receptive. Despite prior participation, some participants in our study expressed distrust of medical researchers and lower willingness for future participation.

Concerns previously identified among minorities that might explain differential participation include control of DNA, potential for misuse of genetic data, racial discrimination, stigmatization, and unequal access to potential benefits. ${ }^{6-9,19,20}$ Such negative views among African Americans are often considered in the context of a historical legacy of discrimination often based on the assertion of genetic inferiority and government funded research such as Tuskegee. ${ }^{21}$ The recruitment and participation of African Americans in research has been a topic of much discussion, given the aforementioned concerns and a continued push to include diverse groups in all human research and the scientific discourse about race and genetic variation. Some have suggested that, given the complexity of the biological specimen requests for genetic studies, decisions to donate may be based less on "informed consent," that is, participant evaluation of the purpose 22 or assessment of the risks and benefits of the specific project. ${ }^{4}$ Rather, general trust that those performing the research will act responsibly may be as important as informed consent. 4,23

These findings, and the concerns described in response to open-ended interview questions, represent potential barriers to recruitment and retention of participants from diverse backgrounds for genomics studies. Interventions that help educate researchers and potential study participants about genetic research and efforts to improve and demonstrate the trustworthiness of the research team might help encourage future study participation. Although a high proportion endorsed interest in future participation, researchers should not assume that prior experience in genetic research completely removes participants' reservations about participation or willingness to donate biological specimens.

Our findings should be viewed in light of its limitations. First, because LeARN participants were drawn from the North Carolina Colorectal Cancer Study, the generalizability of its findings is limited to individuals who have joined similar re- search studies. NCCCS took many measures to demonstrate trustworthiness of the research team and build rapport with potential participants (e.g., 2-hour in-home visits before requests for samples and a recruitment and consent process that involved multiple contacts). Individuals who have not joined such studies may have different and potentially less positive attitudes toward research participation. Additionally, although the LeARN response rate was quite good $(73 \%)$, there are potential biases inherent in the sample that may further limit its generalizability. Although the number of African Americans and whites who refused to participate in the LeARN study was similar, because of unusable telephone numbers, the response rate differed by race. ${ }^{15}$ It is possible that differences between African Americans and whites about how positive they felt about genetic research conceivably could have been larger than we observed had we been able to recruit both races equally.

Despite these limitations, the contributions of LeARN findings are highly relevant to current goals of recruiting genetic study participants. Similar to other reports in the literature, LeARN participants demonstrate a clear willingness for biological specimen donation. This willingness seems, in part, to be driven by trust. Mistrust and concerns about genetic research studies will need to be addressed to ensure diverse future participation.

\section{ACKNOWLEDGMENTS}

This work was supported by NIH Grant No. R01 HG002830-02, NIH/NHGRI Grant No. P50 HG004488, and NIH/NCRR Grant No. U54RR024383.

\section{REFERENCES}

1. McQuillan GM, Porter KS, Agelli M, Kington R. Consent for genetic research in a general population: the NHANES experience. Genet Med 2003;5:35-42.

2. Malone T, Catalano PJ, O'Dwyer PJ, Giantonio B. High rate of consent to bank biologic samples for future research; The Eastern Cooperative Oncology Group experience. J Natl Cancer Inst 2002;94:769-771.

3. Wong ML, Chia KS, Yam WM, Teodoro GR, Lau KW. Willingness to donate blood samples for genetic research: a survey from a community in Singapore. Clin Genet 2004;65:45-51.

4. Kettis-Lindblad A, Ring L, Viberth E, Hansson MG. Genetic research and donation of tissue samples to biobanks. What do potential sample donors in the Swedish general public think? Eur J Public Health 2006;16:433-440.

5. Wang SS, Fred F, Kris MS, Muin JK. Public attitudes regarding the donation and storage of blood specimens for genetic research. Community Genet $2001 ; 4: 18-26$ 
6. Bates BR, Lynch JA, Bevan JL, Condit CM. Warranted concerns, warranted outlooks: a focus group study of public understandings of genetic research. Soc Sci Med 2005;60:331-344.

7. Schulz A, Caldwell C, Foster S. "What are they going to do with the information?" Latino/a and African American perspectives on the Human Genome Project. Health Educ Behav 2003;30:151-169.

8. Fisher CB, Wallace SA. Through the community looking glass: reevaluating the ethical and policy implications of research on adolescent risk and psychopathology. Ethics Behav 2000;10:99-118.

9. Furr LA. Perceptions of genetics research as harmful to society: differences among samples of African-Americans and European-Americans. Genet Test $2002 ; 6: 25-30$.

10. Sterling R, Henderson GE, Corbie-Smith G. Public willingness to participate in and public opinions about genetic variation research: a review of the literature. Am J Public Health 2006;96:1971-1978.

11. Henderson GE, Garrett J, Bussey-Jones J, Moloney ME, Blumenthal C, Corbie-Smith G. Great expectations: views of genetic research participants regarding current and future genetic studies. Genet Med 2008;10:193-200.

12. Murphy J, Scott J, Kaufman D, Geller G, LeRoy L, Hudson K. Public Expectations for return of results from large-cohort genetic research. Am J Bioeth 2008;8:36-43.

13. National Human Genome Research Institute (NHGRI). Design considerations for a potential United States population-based cohort to determine the relationships among genes, environment, and health: recommendations of an expert panel, 2004. Available at: http://www.genome.gov/Pages/About/OD/ ReportsPublications/PotentialUSCohort.pdf. Accessed June 3, 2009.

14. Stegmayr B, Asplund K. Informed consent for genetic research on blood stored for more than a decade: a population based study. BMJ 2002;325:634.
15. Corbie-Smith G, Blumenthal C, Henderson G, et al. Studying genetic research participants: lessons from the "Learning About Research in North Carolina" study. Cancer Epidemiol Biomarkers Prevent 2008;17:20192024.

16. Moorman PG, Skinner CS, Evans JP, et al. Racial Differences in Enrolment in a Cancer Genetics Registry. Cancer Epidemiol Biomarkers Prevent 2004; 13:1349-1354.

17. Schwartz MD, Benkendorf J, Lerman C, Isaacs C, Ryan-Robertson A, Johnson L. Impact of educational print materials on knowledge, attitudes, and interest in BRCA1/BRCA2: testing among Ashkenazi Jewish women. Cancer 2001;92:932-940.

18. Chen DT, Rosenstein DL, Muthappan P, et al. Research with stored biological samples: what do research participants want? Arch Int Med 2005;165: $652-655$.

19. Hoyo C, Reid ML, Godley PA, Parrish T, Smith L, Gammon M. Barriers and strategies for sustained participation of African-American men in cohort studies. Ethnicity Dis 2003;13:470-476.

20. Tambor ES, Bernhardt BA, Rodgers J, Holtzman NH, Geller G. Mapping the human genome: an assessment of media coverage and public reaction. Genet Med 2002;4:31-36.

21. Corbie-Smith G. The continuing legacy of the Tuskegee Syphilis Study: considerations for clinical investigation. Am J Med Sci 1999;317:5-8.

22. Hoeyer K. 'Science is really needed-that's all I know': informed consent and the non-verbal practices of collecting blood for genetic research in northern Sweden. New Genet Soc 2003;22:229-244.

23. Siegrist $M$. The influence of trust and perceptions of risks and benefits on the acceptance of gene technology. Risk Anal Int $J$ 2000;20:195-204. 